\title{
EL AGUA Y EL SUELO EN LA ZONA METROPOLITANA DEL VALLE DE MEXICO
}

\author{
Alfonso Iracheta Cenecorta \\ Arquitecto, Miembro del Sistema Nacional de Investigadores. \\ Actualmente ocupa la presidencia de El Colegio Mexiquense.
}

\begin{abstract}
Resumen: La ciudad de México representa uno de los ejemplos más dramáticos de la lucha del hombre por dominar a la naturaleza al grado de transformarla de manera profunda, sin tener claridad sobre los efectos de estas transformaciones. Al inicio del siglo 21 ha concentrado una población del orden de 19 millones de habitantes y se han urbanizado casi 2 mil kilómetros cuadrados. Los patrones de asentamiento dentro del Valle de México han generado impactos negativos que en la actualidad ponen en riesgo el futuro de la metrópoli. Palabras clave: metropolización en Latinoamérica; ciudad de México; agua y el suelo.
\end{abstract}

E n 1971 inicié el proyecto de tesis de licenciatura para alcanzar el grado de arquitecto, la que titulé "Ciudad Texcoco". Estaba inspirada en la experiencia reciente de diversos estudios y proyectos urbanísticos que estábamos desarrollando en el naciente Instituto Auris del gobierno del Estado de México.

Pretendía ofrecer el proyecto de una nueva ciudad que se adelantara al caos urbano que ya se vislumbraba a partir de las experiencias de crecimiento urbano en los municipios de Ecatepec y Nezahualcóyotl, conurbados con la ciudad de México. También buscaba vincular el nuevo desarrollo al proyecto de la Comisión de Estudios del Lago de Texcoco (CELT) y a la preservación de la cuenca lechera de esta región.

El ejemplo del proyecto de la nueva ciudad Cuautitlán Izcalli ${ }^{1}$ era sin duda sumamente atractivo porque demostraba que existían la voluntad política, los recursos y la técnica para responder proporcionalmente al inmenso reto de la metropolización del valle de México.

¿Porqué esta remembranza?. En primer lugar porque aquellas tierras de mi proyecto de tesis están en buena medida hoy ocupadas o en proceso de ocupación para usos urbanos, bajo la ley intocable del mercado formal y del mercado informal de suelo.

En segundo lugar porque Cuautitlán Izcalli no fué la solución que pensamos entonces, no porque no se haya construído, sino porque habiéndose realizado en buena parte, nunca se consideró la necesidad de políticas de suelo para preservar y prever la ordenación de los espacios intersticiales entre ella y la mancha continua de la metrópoli, con lo cual se provocó la conurbación indeseada y desordenada del corredor que llega hoy hasta el municipio de Tepotzotlán en el Estado de México, en la colindancia con el Estado de Querétaro.

Tampoco se aprovechó suficientemente la oportunidad histórica que se tuvo al expropiarse del orden de $10 \mathrm{mil}$ hectáreas de terrenos ejidales ${ }^{2}$ para crear con este suelo reservas para derechos de vía, para infraestructuras y equipamientos o para preservación ambiental.

No se resolvió la necesidad de transporte masivo para el nuevo asentamiento proyectado para más de 1.5 millones de habitantes, como tampoco se atendieron o previeron los impactos que en términos hidráulicos generaría el desarrollo.

Esta es la historia de esta nueva ciudad y en general de los nuevos desarrollos planificados y diseñados por los mejores técnicos que el país tiene. Es decir, pareciera ser que, mágicamente, el mercado de suelo localiza a la población y a las actividades urbanas de manera eficiente y socialmente adecuada; pareciera que "naturalmente" las necesidades de transporte masivo se resuelven, sin que sea necesaria una intervención enérgica del gobierno; pareciera que el agua es un recurso no solo renovable sino ilimitado, por lo que habrá siempre una acción pública que ponga 
el vital líquido a la puerta de nuestra vivienda, sin que exista más responsabilidad del desarrollador, propietario o vecino, que pagar, eventualmente, una cuota.

El argumento que hace falta discutir es entonces esta relación fundamental, entre las políticas de agua en el valle de México y el proceso de ocupación, tenencia, apropiación y mercadeo del suelo, al que insistentemente considero el elemento estratégico para el desarrollo urbano, porque quien lo controla, controla también el proceso de urbanización.

\section{LOS IMPACTOS Y PERSPECTIVAS DE LA URBANIZACION DEL VALLE DE MEXICO}

La ciudad de México representa uno de los ejemplos más dramáticos de la lucha del hombre por dominar a la naturaleza, al grado de transformarla de manera profun$\mathrm{da}$, sin tener claridad sobre los efectos de estas transformaciones. De una cuenca cerrada con grandes extensiones de agua, a lo largo de casi cinco siglos se convirtió en un valle abierto. Al inicio del siglo 21 ha concentrado una población del orden de 19 millones de habitantes y se han urbanizado casi dos mil kilómetros cuadrados.

Los patrones de asentamiento dentro del Valle de México han generado impactos negativos que en la actualidad ponen en riesgo el futuro de la metrópoli.

Desde el punto de vista económico, el patrón de asentamiento urbano disperso a lo largo de la periferia metropolitana y las carencias de infraestructura, multiplican los costos con relación a un desarrollo previamente planeado; la consecuencia de este patrón es una localización ineficiente de los recursos de la sociedad para el desarrollo urbano; un desperdicio que el país no puede aceptar.

Desde el punto de vista social, el desorden urbano genera costos crecientes que no pueden ser pagados por los pobres de la ciudad. Cuando se convierten en propietarios de suelo en asentamientos irregulares, pierden una parte importante de su ingreso. Esto ocurre por la compra ilegal de un pedazo de suelo, su regularización posterior, el pago de costos crecientes de servicios urbanos y el involucramiento de los colonos como trabajadores en obras públicas de participación, como camino casi único para acceder a servicios básicos.

Desde una perspectiva ambiental, el proceso de urbanización tiende a destruir los recursos naturales.

En primer lugar está la crisis del transporte. La congestión urbana continua, adicionada con la ineficiencia del transporte público, dominado por vehículos de baja capacidad y muy contaminantes, además de la concentración dentro de la metrópoli de algunas empresas con altas emisiones a la atmósfera, reduce sensiblemente la calidad del aire.

La creciente falta de funcionalidad de la metrópoli, impone sobre la población viajes intraurbanos cada vez más largos debido a las siguientes razones:

- la estructura urbana en forma radial, con una intensa dependencia de la periferia sobre la infraestructura y el equipamiento del centro de la metrópoli (ciudad de México). La consecuencia es que la mayor cantidad de viajes diarios que se realizan en la ZMVM, tienen como destino la zona centro de la ciudad;

- el gran desbalance entre el empleo y la localización y concentración de las áreas de residencia. La ineficacia de las políticas públicas para localizar las actividades urbanas y la población con criterios de ordenamiento urbano ha llegado a extremos, ya que una parte importante de la ocupación urbana en los municipios metropolitanos del Estado de México solo se destina a vivienda de baja renta, convirtiéndose en áreas dormitorio.

Estos problemas se han agudizado por la baja calidad del transporte público, existiendo en casi toda la mancha metropolitana problemas de congestión de tráfico que en muchos lugares han alcanzado niveles intolerables. Desde otra perspectiva, los trabajadores tienen que soportar hasta cuatro horas de trayecto durante el día para acceder al centro de trabajo y regresar a casa, en un transporte que no ofrece las condiciones adecuadas.

En segundo lugar está el deterioro de las áreas forestales y la pérdida de áreas agrícolas; estos fenómenos reducen la producción de oxígeno, las posibilidades de recreación a cielo abierto y el turismo, además de provocar cambios en el clima del valle. Lamentablemente, la mayoría de las actividades productivas agropecuarias y forestales pierden económicamente ante las perspectivas especulativas que ofrece el mercado inmobiliario.

En tercer lugar está el problema del agua. La reducción del nivel freático y la contaminación del agua, así como la insuficiente infraestructura sanitaria y la destrucción de áreas de recarga de acuíferos, están poniendo en riesgo los planes públicos de protección y recuperación del ambiente en la metrópoli.

El Valle de México es importador neto de agua de otras cuencas, destacando las de los ríos Lerma y Cutzamala en el Estado de México, no obstante que la explotación de los acuíferos locales sigue siendo sumamente intensa. 
El desperdicio de agua por la falta de una estructura social y de infraestructura que permita su aprovechamiento racional, la sobreexplotación de los acuíferos del valle, la falta de políticas de reutilización y la continua urbanización y reducción de espacios para la infiltración, ha puesto al valle en condiciones de crisis hidráulica desde hace varias décadas.

Desde el punto de vista político, la serie de efectos negativos de un proceso de urbanización desordenado, han acelerado el incremento de las protestas de la comunidad, de diversas organizaciones sociales y de los partidos políticos. El promedio diario de protestas callejeras, solamente en el Distrito Federal, durante 1995 alcanzó prácticamente 7 , involucrando una participación total de más de 1.2 millones de ciudadanos irritados (Iracheta, 1997).

Igualmente, este proceso explica aunque sea parcialmente, los resultados electorales plurales en las elecciones locales de 1996, 1997 y 2000, no solo en el Distrito Federal, sino también en los municipios y distritos electorales del Estado de México.

La concentración urbana dentro de la ZMVM continuará en el futuro, aunque a tasas de crecimiento poblacional decrecientes.

La metrópoli mantendrá el papel central que ha tenido en casi todos los grandes asuntos del desarrollo nacional. Esta posición seguramente que no cambiará, al menos en el futuro cercano. Su población prevista para el año 2020, de acuerdo con el escenario planificado reconocido por las autoridades de la metrópoli (ver: Programa de Ordenación de la Zona Metropolitana del Valle de México), será de alrededor de 22 millones de habitantes. Para el mismo año y de acuerdo con el escenario tendencial, la población esperada será de cerca de 26.2 millones de habitantes. Es decir, un incremento de 4.9 o 9.2 millones sobre la población de 1995.

Este proceso implica que la metrópoli ocuparía del orden de 218 mil (2,180 kilómetros cuadrados) o $262 \mathrm{mil}$ hectáreas (2,620 kilómetros cuadrados) respectivamente, considerando que persistirá en esencia el patrón de poblamiento actual, lo que podría implicar que los problemas que se generarán, rebasarán los límites tolerables de habitabilidad en la metrópoli.

Una primera conclusión que requiere ser asumida, es que la ZMVM desde el punto de vista geográfico, enfrenta una crisis derivada de la ocupación indiscriminada de su suelo. Pareciera ser que no existe un proyecto acordado y que se esté aplicando para atender los rezagos y pro- blemas actuales y para atender las necesidades de la nueva población.

Si con cerca de 19 millones de habitantes (2001), ya existe una apreciación generalizada para la metrópoli de que ha entrado en una fase crítica de desarrollo, al grado de poner en riesgo su futuro. Con cerca de 50 por ciento más población y bajo la lógica de asentamiento actual, es muy probable que la crisis podrá derivar en acciones sociales desestabilizadoras.

\section{LA METROPOLI Y EL AGUA}

La cuenca de México se integraba por 1.100 kilómetros cuadrados de lagos: Texcoco, Chalco, Xochimilco, San Cristóbal - Xaltocan y Zumpango, equivalentes a la superficie urbanizada de la Zona Metropolitana del Valle de México, en 1990.

Desde su origen, Tenochtitlán enfrentó la contradicción de su localización al fundarse en la parte baja del lago de Texcoco; esta contradicción se hizo evidente a través de los sufrimientos a que fue sometida la ciudad por los desbordamientos de este lago.

Hacia 1450 el rey Nezahualcóyotl construyó un albarradón de 12 kilómetros de largo por 4.5 metros de ancho para proteger a la ciudad de estos desastres. Los conquistadores fueron los que determinaron la transformación de la cuenca en valle, al construir las obras de desague del valle de México.

Como mencionan las crónicas de Carrasco (1998) y Barranco (1998), en el año 1609, como consecuencia de las inundaciones que la capital de México había sufrido a causa de las crecientes del río Cuautitlán, el cosmógrafo alemán Heinrich Martin (Enrico Martínez) propuso la construcción de un túnel de 7 kilómetros de largo a 50 metros de profundidad en promedio, en el norte del valle de México, en un sitio llamado Huehuetoca; este dren, desde entonces, se ha llamado "Tajo de Nochistongo" correspondiente a la denominación del paraje que limita los dos valles. La inmensa obra se inició el 28 de noviembre de 1607 , con una primera palada por el virrey Luis de Velasco y siguiendo el ritual eclesiástico con misa solemne. Fue este el primer intento para desalojar el agua del valle de México. Para construir este dren, fue necesario perforar las montañas "a mano", con la participación de más de 471 mil trabajadores, a fin de que las aguas del lago de Zumpango fueran drenadas al valle de Tula y recogidas por tres ríos: el Tula, el Moctezuma y el Pánuco, para desembocar en el Golfo de México. 
Para el propio Enrico Martínez, esta era apenas la primera de cuatro etapas. Sin embargo, ante las presiones del Ayuntamiento para continuar las obras que conjurarían el permanente peligro de inundación y previa opinión en contra del perito Alonso de Arias, quien aseveró que la estrechez del canal de Huehuetoca impedía mejorar su función o incluso conservarlo para el futuro, el virrey expidió el 11 de mayo de 1611 una cédula especial, en la que declaraba que las medidas para la obra estaban equivocadas $y$, en consecuencia, se había gastado en vano (Barranco, 1998). En 1614 el francés Adrián Boot consideró que el canal era insuficiente y que apenas serviría para evitar las inundaciones provocadas por las crecientes del río Cuautitlán.

Hacia 1616, el virrey marqués de Guadalcázar autorizó nuevamente a Martínez a continuar las obras, aunque estas se suspendieron dos años después, regresando a la construcción de diques. Estos, sin embargo, fueron destruídos por otra inundación en 1627. Enrico Martínez fue sometido a juicio del que salió absuelto, “(...) recobrando su libertad el día de San Mateo Evangelista de 1629" (Barranco, 1998). Es decir, el día de la gran inundación.

“(...) Desbordada la ira de la naturaleza todo el mediodía y toda la tarde del 21 de septiembre de 1629 , por la noche eran ya pantanos los arrabales de Peralvillo, Santiago Tlatelolco, la Bolsa y Romita. Y a los primeros toques del alba, empezó a escucharse el rugido acechante del río de Cuautitlán, en desigual lucha contra la falda del cerro de Nochistengo (sic) y los diques de la ciudad...para vencerlos finalmente en la mañana más gris de la Nueva España, desparramando su victoria hasta volver una de las lagunas de Citlaltepec y Zumpango (...) sin que por ello parara la lluvia (...) Dos días después, rendidas al fin las nubes, el agua, de las tres antiguas calzadas de Guadalupe, Tacuba y San Antón, de la Piedad a Chapultepec, de Belén a San Cosme, y del Palacio Virreynal a la Garita de Peralvillo, subía dos varas, es decir alcanzaba el cuello del soldado más alto (...)" (Barranco, 1998).

El tamaño de esta tragedia fue inmenso. Alcanzó 30 mil indios muertos por el agua, los derrumbes o el hambre por lo que cinco años después, plagada la ciudad de pantanos, charcos pestilentes y lodazales, solo quedaban 400 familias de españoles o criollos de las 20 mil que existían en 1624 (Barranco, 1998).

Hacia 1631, y con las aguas cubriendo buena parte de la ciudad, el virrey Lope Díez de Armendariz, marqués de Cadereyta, “(...) nombraría como juez superintendente del desagüe al oidor Juan Villabons Cubiarse, quien descalificaría radicalmente la obra del extranjero" (Barranco, 1998).

Las diferencias que a lo largo de este periodo se expresaron frente al fenómeno, fueron la consecuencia de la falta de un proyecto claro para resolver la contradicción planteada por la necesidad de seguir construyendo la ciudad y al tiempo reducir los riesgos de inundaciones; fueron también el producto de la preeminencia de los intereses económicos y políticos sobre las necesidades de una solución de largo plazo. Una evidencia de ello, fue la falta de respuesta de la sociedad de la ciudad de México cuando, ante las sucesivas crisis provocadas por las inundaciones, se puso sobre la mesa de la discusión el viejo proyecto del rey de España de trasladar la metrópoli de la Nueva España a un lugar más alto (Puebla), sin que tuviera eco por los grandes intereses económicos ya asentados en el comercio y las tierras del valle.

Otra obra fundamental para drenar el agua fue el Gran Canal del Desagüe, iniciado por Maximiliano en 1867 y culminado por Porfirio Díaz en 1900. Las obras “(...) consistieron en la construcción de un canal abierto de 43 kilómetros y un túnel de 11 kilómetros de largo y 4.5 metros de diámetro, a 100 metros de profundidad. La parte abierta va de San Lázaro a Zumpango, mientras que el túnel corre del río Tula al Moctezuma y de allí al Pánuco, en el Golfo de México. La función del gran canal fue la de secar otros lagos de la ciudad: el de Texcoco y el de San Cristóbal - Xaltocan” (Barranco, 1998).

Otra gran inundación ocurrió en 1901, apenas inaugurado el gran canal. En 1951 la ciudad estuvo inundada por tres meses. En el Centro Histórico el agua alcanzó metro y medio.

En una época, las inundaciones fueron el producto del desbordamiento de lagos y ríos; no obstante que la cuenca prácticamente se secó, las inundaciones continúan en la actualidad.

Estas últimas inundaciones son más bien el producto del agotamiento de los manantiales y la extracción de agua por pozos profundos; es decir, se generan por el hundimiento del suelo que, a lo largo del siglo, ha alcanzado, en el centro de la ciudad, del orden de 9 metros. Por ello, el drenaje que se proyectó para operar por gravedad, requiere un sistema de bombeo para alcanzar el nivel del gran canal del desagüe.

La tercera gran obra es el drenaje profundo que se inició en 1975. Si bien opera por gravedad, los sedimentos que arrastran los 14 ríos y arroyos que bajan agua de la Sierra 
del Poniente del valle, azolvan constantemente la red que lo alimenta. Este sistema cubre $94 \%$ de la ciudad y tiene 161 kilómetros de túneles. La tubería tiene diámetros de 3.5 a 8 metros. Su profundidad va de 15 a 220 metros y tiene una capacidad de conducción de 220 metros cúbicos por segundo de aguas servidas y pluviales.

Esta obra está diseñada para ser el ducto central para desalojar el agua del valle, ya que el gran canal del desagüe dejará de ser operativo en pocos años. Las obras deberán terminar en el año 2010.

Una imagen del significado de estas obras es que la capacidad de recarga del valle de México, del orden de 270 millones de metros cúbicos, de los que se drenan cada año hacia el Golfo de México 200 millones de aguas de lluvia.

Para desalojar estos volúmenes de agua, se ha desarrollado una infraestructura consistente (1998) en:

- 85 plantas de bombeo con capacidad para 670 metros cúbicos por segundo;

- 17 presas de almacenamiento y 10 lagunas de regulación con capacidad para 11 millones de metros cúbicos;

- 129 kilómetros de ríos;

- 47 kilómetros de cauces (ríos) entubados.

Contradictoriamente, se importa agua de cuencas lejanas y no se han desarrollado obras para retener y aprovechar parte de este caudal. En materia de agua potable, la ZMVM dispone de 67 litros por segundo, de los que los municipios conurbados del Estado de México disponen de 29 ( $25 \%$ por debajo de sus necesidades) y el Distrito Federal (ciudad de México) dispone de 38. La necesaria veda de pozos implica, cada día, incrementar la importación de caudales de fuentes más lejanas y a costos difíciles de sostener.

La urbanización adicional estimada para el valle de México, con base en las proyecciones de los dos escenarios - tendencial y planificado - hacia el año 2020, implicará la adición de aproximadamente $8.7 \mathrm{~m}^{3} / \mathrm{seg}$ de agua potable o bien $9.1 \mathrm{~m}^{3} / \mathrm{seg}$, según cada uno de los escenarios señalados, para atender las necesidades de la nueva población. Lo que permite prever que deberá agudizarse la crisis hidráulica que, de muchas décadas atrás, rebasó a la cuenca de México.

Entre todas las acciones realizadas a lo largo de su historia, solamente el proyecto Lago de Texcoco ha pretendido combinar las necesidades de urbanización del valle con su origen lacustre. Su objetivo fue restaurar el equilibrio hidrológico del valle, construyendo seis lagos reguladores. El proyecto ocupó en sus orígenes del orden de 14 mil hectáreas en las que, además de los lagos, se pretendía desarrollar pastizales, áreas arboladas y de atracción turística, además de una ampliación al aeropuerto internacional de la ciudad de México (Iracheta, 1974).

La CELT (Comisión de Estudios del Lago de Texcoco), también planteó obras importantes que permitirían reducir las inundaciones al regular las aguas, al tiempo que se proponía un sistema de abastecimiento para consumo y de reciclaje de aguas servidas para usos no domésticos. El lago Nabor Carrillo fue el único que se realizó. Su nombre recuerda al ingeniero que coordinó dicho proyecto.

En conclusión, si buscáramos sintetizar la relación entre la metrópoli y el agua, seguramente que habría acuerdo en que ha sido y seguirá siendo contradictoria y paradójica, porque la historia ha demostrado la incapacidad de la sociedad para ofrecer respuestas a un fenómeno urbano que, en principio, nunca debió haber ocurrido en el valle de México, cuando menos en las proporciones a las que ha llegado y las que se estima alcanzará en el futuro.

Resulta sorprendente que las acciones de gobierno y de la sociedad continúen presionando hacia la concentración de actividades y población. Desde el inicio de los 90 se planteó una propuesta de desarrollo integrado para el valle de México que abarca además la región central del país - la megalópolis de la ciudad de México -; esta propuesta culminó con la integración del Programa de Ordenación de la Zona Metropolitana del Valle de México, que en marzo de 1998 fue aprobado por el gobernador del Estado de México y el jefe de gobierno del Distrito Federal, con lo cual se dio un paso trascedental al materializarse por primera vez un proyecto metropolitano compartido por dos entidades federativas.

Sin embargo, a diferencia de otras metrópolis del mundo, en el caso de la ZMVM no ha existido desde el gobierno federal una clara intención para enfrentar este fenómeno que es de los más costosos para la nación.

No es solo cuestión de corregir todos los problemas que implica la sobreexplotación de los mantos acuíferos del valle y el hundimiento de la ciudad, de por sí muy costosos; o introducir servicios públicos en sitios en que los pobres se han asentado y que representan riesgos altos de inundación y de incapacidad mecánica del suelo para dichas infraestructuras, como en el oriente del valle en torno al ex lago de Texcoco; o importar agua de cuencas lejanas como Lerma y Cutzamala secándolas, como está ocurriendo en la primera, y reduciendo sensiblemente la capacidad de extracción y de generación de energía 
eléctrica, como ya está ocurriendo en el Sistema Hidráulico Miguel Alemán, al que pertenece la segunda.

El costo de construcción y mantenimiento de infraestructura desde las otras cuencas y de bombear agua más de mil metros para salvar montes y sierras, y, al tiempo seguir drenando el agua de lluvia del valle, ¿son acciones razonables?. ¿No resulta más lógico intentar recuperar, aunque parcialmente, a la ciudad lacustre?

\section{¿QUÉ HACER FRENTE A LA URBANIZACION DEL VALLE DE MEXICO?}

Enfrentar un fenómeno tan dinámico y complejo, requiere tener en mente que los actuales mecanismos de planeación, financiamiento y administración pública de la metrópoli han mostrado que son insuficientes e inadecuados.

Se debe también tomar en cuenta que la historia reciente de la acción gubernamental y social ha mostrado grandes deficiencias para reducir la crisis metropolitana, especialmente en el manejo del suelo, del agua y del transporte. Ante esta historia de políticas fallidas, se requiere enfrentar, cuando menos, los efectos más negativos del proceso de urbanización dentro de un contexto metropolitano y reestructurar, modernizar y modificar los procesos, las prioridades y las formas de ejecución de las políticas urbanas.

Es esencial reducir la velocidad de expansión urbana dentro del Valle de México y organizar el crecimiento urbano futuro de manera que se reduzcan los impactos negativos. En este sentido, las propuestas para el desarrollo metropolitano deben partir de dos premisas:

- por un lado, se requiere reconocer que, independientemente de las acciones para detener el crecimiento urbano, la ZMVM seguirá poblándose aunque a tasas menores, siendo indispensable prepararse para ello;

- segundo, resulta indispensable contar con un proyecto de largo plazo para la metrópoli desde una perspectiva regional evitando que continúe el patrón de ocupación actual;

- tercero, destaca la necesidad de asumir el proceso de construcción de la ciudad, a partir de propuestas integrales, cuya esencia debe ser el determinar, de una vez por todas, donde sí y donde no urbanizar y realizar todo lo necesario para que en la práctica social se respete. Espacialmente, implica cumplir con las siguientes políticas:

- creación de nuevos asentamientos desconcentrados, en la forma de nuevas ciudades o corredores, promoviéndose simultáneamente en su entorno actividades agropecuarias y las que permiten mantener grandes espacios abiertos que eviten su conurbación con otros asentamientos.

- consolidar y reordenar la ocupación dentro del área urbanizada, tanto en el Distrito Federal como en los municipios del Estado de México, ocupando los baldíos y evitando la expansión de la mancha urbana como mancha de aceite.

- acordar un proceso de ocupación urbana en nivel regional con las entidades vecinas al Distrito Federal, especialmente en la llamada "corona de ciudades", a fin de definir, bajo criterios homogéneos, el futuro de la metrópoli de metrópolis o megalópolis del centro del país.

La esencia del proceso es reconocer al suelo como el elemento central en torno al cual es posible articular políticas de largo plazo, si se cuenta con los instrumentos para su utilización racional y control.

Esta profunda transformación debe fundarse en respuestas más coherentes a las que se han tenido hasta hoy. Los nuevos programas y políticas deberán reconocer que no existen en México suficientes instituciones capaces de articular acciones desarrolladas por las dependencias gubernamentales, propietarios de suelo, inversionistas y la sociedad, para emprender programas integrales metropolitanos que tengan como eje al suelo.

Igualmente, deberán orientarse a asegurar una distribución más equilibrada de costos y beneficios; a hacer efectivo el derecho de los pobres a tener oportunidades de desarrollo y un espacio donde habitar, y, a preservar y explotar sustentablemente los recursos naturales entre los que sin duda destaca el agua.

Los programas y las políticas deben fundarse en la aceptación de la necesidad de un nuevo modelo de desarrollo metropolitano, al igual que nuevos roles para los agentes sociales, económicos y públicos involucrados en el desarrollo metropolitano, definiendo para cada uno de manera clara sus derechos y obligaciones.

Hoy la sociedad, a través de organizaciones no gubernamentales, ha asumido diversas responsabilidades asociadas al desarrollo de las ciudades, cubriendo espacios que el Estado ha dejado sin atención. Por eso, muchos agentes sociales deben enfrentar nuevos roles, más activos y más creativos.

El Estado, al retraerse de diversas funciones relacionadas con la producción de la ciudad, debe, por una parte, 
consolidar su papel de orientación, facilitación y conducción del desarrollo en general y del desarrollo urbano en especial y, por la otra, dejar espacios claramente acordados, para la acción de los inversionistas y las organizaciones de la sociedad en el proceso de urbanización.

En conclusión, pareciera ser claro que, el problema del agua en el valle de México, no es causa, sino consecuencia, del proceso caótico de urbanización nacional y regional. Atender el problema del agua implica necesariamente atender, primero, las causas de esa urbanización depredadora y consumidora irracional de agua. Estando estas causas ubicadas en la forma en que México se ha desarrollado durante las últimas cinco décadas y una vez que existe una inercia que no tiene posibilidades de ser revertida, cuando menos en el mediano plazo, es necesario sentar nuevas bases para la urbanización.

Para estipular esas nuevas bases, se requiere entender que el factor central para controlar el proceso es el suelo y su mercado, ya que por medio de reglas socialmente orientadas o bien individualmente determinadas respecto a la apropiación, mercadeo, utilización y explotación del suelo, es que pueden existir mejores condiciones de hacer de la urbanización un proceso eficiente para el desarrollo y no, como está llegando a ser en el valle de México, eficiente solo para algunos intereses privados e ineficiente para el conjunto de la sociedad nacional y local.

En este contexto, la crisis hidráulica puede adquirir visos de solución en el futuro, si a través de una política de suelo se urbaniza donde resulta adecuado desde la perspectiva de la sustentabilidad del recurso.

Igualmente si se crean condiciones para retener agua de lluvia y aprovecharla, lo que puede implicar utilizar grandes superficies de tierra para ello; situación que en la actualidad la especulación para usos urbanos del suelo y la incertidumbre del uso a que cada pedazo de suelo está destinado lo impiden. Evidencias de ello son la ocupación por ejemplo, del valle de Chalco al oriente de la metrópoli, espacio que pudo haber sido parcialmente un reservorio natural de agua y que, en la actualidad, se ha convertido en un gigantesco asentamiento irregular con graves pro- blemas para la introducción de infraestructura por la baja capacidad mecánica de los suelos, lo que deriva de haber sido en el pasado un lago.

Finalmente, si independientemente de los intereses ya establecidos se asumen políticas de desconcentración y descentralización de actividades y población metropolitana, creando, con los inversionistas y desarrolladores, grandes reservas de suelo donde sí se puede construir ciudad, y, evitando enérgicamente la ocupación de los espacios que ecológicamente deban tener otros usos.

\section{NOTAS}

1. Este proyecto se basó en las experiencias europeas de nuevas ciudades en torno a las metrópolis. Puede ser considerado como el mayor esfuerzo mexicano para enfrentar de manera planificada el desarrollo metropolitano, no solo porque se planteó asentar a más de un millón de habitantes, sino porque contó con recursos y voluntad política reales para su construcción que alcanzó del orden de $80 \%$ de lo previsto.

2. Modalidad de tenencia de la tierra cuyo origen es prehispánico y que fue el mecanismo para la reforma agraria nacional que derivó de la revolución de 19101917. Los campesinos beneficiados (ejidatarios), hasta las reformas a la Ley de Reforma Agraria de 1992, no eran propietarios, aunque tenían dominio real sobre la tierra. Al dotarse de ejidos la periferia de las ciudades, fueron ocupados conforme se expandieron las áreas urbanas, creando por un lado, un inmenso fenómeno de ilegalidad en la tenencia de la tierra y ofreciendo por otro, una salida social a las necesidades de suelo de los pobres de la ciudad, no resueltas por el Estado ni por el mercado inmobiliario legal.

\section{BIBLIOGRAFÍA}

BARRANCO, C. “Ciudad y Metrópoli”. Periódico Reforma. México, D.F., Grupo Reforma, 11/oct./1998, p.7B.

CARRASCO, J. “Ciudad y Metrópoli”. Periódico Reforma. México, D.F., 4/oct./ 1998, p.6B.

CONSEJO NACIONAL DE POBLACIÓN. Escenarios demográficos y urbanos de la Zona Metropolitana de la Ciudad de México 1990-2010. México, 1998.

GAMBOA, J. Ciudad de México, una visión. México, 1994.

GARCÍA, A. Atlas geográfico, estadístico e histórico de la República Mexicana. México, Antigua Imprenta de Murguía, 1887.

GARZA, G. Atlas de la ciudad de México. México, Departamento del Distrito Federal, El Colegio de México, 1986.

IRACHETA, A. Ciudad Texcoco. Tesis profesional de arquitecto, Toluca, México, Escuela de Arquitectura, UAEM, 1974.

Planeación y desarrollo, una visión del futuro. México, D.F., Plaza y Valdés Editores, 1997.

LÓPEZ, D. Atlas histórico geofráfico de México 1940. México, 1940. 